\title{
Study on Strength and Microstructure of Cement Pastes Containing Limestone Powder under Flowing Acid Solution Condition
}

\author{
Shuhua Liu, ${ }^{1}$ Lihua Li, ${ }^{2}$ Zhigang Wang, ${ }^{1}$ Jiafeng Wang, ${ }^{1}$ and Meijuan Rao ${ }^{3}$ \\ ${ }^{1}$ State Key Laboratory of Water Resources and Hydropower Engineering Science, Wuhan University, Wuhan 430072, China \\ ${ }^{2}$ School of Civil Engineering and Architecture, Hubei University of Technology, Wuhan 430068, China \\ ${ }^{3}$ Department of Civil and Earth Resources Engineering, Kyoto University, Kyoto 615-8540, Japan
}

Correspondence should be addressed to Shuhua Liu, shliu@whu.edu.cn

Received 15 August 2012; Accepted 7 September 2012

Academic Editors: K. L. Bing and H. I. Hsiang

Copyright () 2012 Shuhua Liu et al. This is an open access article distributed under the Creative Commons Attribution License, which permits unrestricted use, distribution, and reproduction in any medium, provided the original work is properly cited.

\begin{abstract}
Different cement pastes containing limestone powder were prepared and soaked, respectively, in flowing acetic acid solution with $\mathrm{pH}$ value of 4 and sulfuric acid solution with $\mathrm{pH}$ value of 2 . The strength and microstructure of the pastes after different flowing acid attack periods were investigated by using strength test, X-ray diffraction (XRD), and scanning electron microscopy (SEM) techniques in this study, which reveals the effect of limestone powder on flowing acid resistance mechanism of cement paste. Testing results show that the strength of pastes suffered flowing acid attack decreases with the increase of water-binder ratio and the content of limestone powder. In flowing acetic acid solution, calcium hydroxide and calcium carbonate react with acetic acid, which therefore made deterioration of pastes proceed from the exterior to the interior. In flowing sulfuric acid solution, although calcium hydroxide and calcium carbonate could react with sulfuric acid and form gypsum, the flowing liquid would dissolve it out and thus the crystallization of gypsum was difficult which would somewhat inhibit the swell of pastes.
\end{abstract}

\section{Introduction}

Concrete and mortar are always affected by physical and chemical attack under environmental water conditions and therefore their microstructure will be deteriorated, strength of the structure will decrease, and finally the architectures will be destroyed $[1,2]$. There are mainly five kinds of environmental water attack, among which the acid attack is the most common. Acidic materials are such widely spread as in the atmosphere, in the soil contiguous with buildings, in the industrial wastes, and in the marine environments. Cement paste as an alkali compound is easily to be corroded under acid attack.

Modern cements often incorporate several mineral admixtures, one of which is limestone powder. The use of Portland cement containing limestone powder is a common practice in Europe. European standard EN 197 identifies two types of Portland limestone cements (PLC): type II/A-L containing 6\%-20\% and Type II /B-L containing 21\%-35\%
[3-5]. The use of limestone powder can improve properties of concrete, decrease the costs, and reduce $\mathrm{CO}_{2}$ and $\mathrm{NO}_{x}$ emissions during cement manufacture [6-8]. But there are still problems concerning the application of concrete mixed with limestone powder. The main composition of limestone powder is calcium carbonate which is easily to be suffered from acid attack. Although they have been implemented about this kind of concrete, most of the researches were limited to the static erosion environment [9-12]. While in practical projects, the concrete structures such as piers and foundations are usually located where the seepage of groundwater is positive or the erosion of the flowing water is intense. How the flowing acid attack resistance of cement paste changes after incorporating limestone powder still remains uncertain.

In this paper, cement pastes with different mix proportions and different contents of limestone powder were prepared. These pastes were then soaked in the flowing acetic acid solution with $\mathrm{pH}$ value of 4 and sulfuric acid solution 
with $\mathrm{pH}$ value of 2 , respectively. The changes of strength and microstructure of pastes after different flowing acid attack periods were investigated by using strength test, X-ray diffraction (XRD), and scanning electron microscopy (SEM) techniques, which will indicate the effect of limestone powder on flowing acid attack resistance mechanism of cement paste.

\section{Experimental}

2.1. Raw Materials. The mixtures were prepared with ordinary Portland cement PO 42.5 (the Chinese standard GB1752007), limestone powder, fly ash, and silica fume. Limestone powder, produced from carboniferous limestone with a very high purity ( $95 \%$ of $\mathrm{CaCO}_{3}$ content), was added as filler. The particle size distribution of Portland cement, limestone powder, and fly ash measured by laser diffraction is shown in Figure 1. Obviously, the particle size of limestone powder is much smaller than those of Portland cement and fly ash. The dominant particle size of limestone powder is below $5 \mu \mathrm{m}$.

2.2. Mix Proportions. In order to study the effect of limestone powder on flowing acid attack resistance of cement paste, two different water-binder ratio serials including the low value of 0.3 and the high value of 0.5 were set. By changing the content of limestone powder and mixing with fly ash or silica fume, 10 different pastes were prepared. The specific mix proportions are shown in Table 1.

Paste specimens with size of $20 \times 20 \times 20 \mathrm{~mm}^{3}$ were cast according to Table 1 . After molding 24 hours, the pastes were removed from the mold and then placed for standard curing till $28 \mathrm{~d}$ when their strength was tested as reference. Thereafter, they were soaked in two different solutions: the flowing acetic acid solution with $\mathrm{pH}$ value of 4 and the flowing sulfuric acid solution with $\mathrm{pH}$ value of 2 . The strength change, XRD, and SEM analysis were studied, respectively. The actual devices simulating flowing solution environment are shown in Figure 2.

2.3. XRD. XRD measurements were implemented on a Philips X'Pert diffractometer equipped with a graphite monochromator using $\mathrm{Cu} \mathrm{K} \alpha$ radiation and operating at $40 \mathrm{kV}$ and $20 \mathrm{~mA}$. Step scanning was performed with a scan speed of $2^{\circ} / \mathrm{min}$ and sampling interval of $0.02^{\circ} / 2 \theta$. XRD was used to identify the hydrates in the cement pastes containing limestone powder.

\section{Results and Discussions}

3.1. Strength. The compressive strength of the pastes soaked in flowing acid solution for different periods is shown from Figure 3 to Figure 6. It can be concluded from the four diagrams that compressive strength of the pastes would firstly decrease and then increase slightly and finally decrease again. The strength would decrease correspondingly with the increase of water-binder ratio and the content of limestone

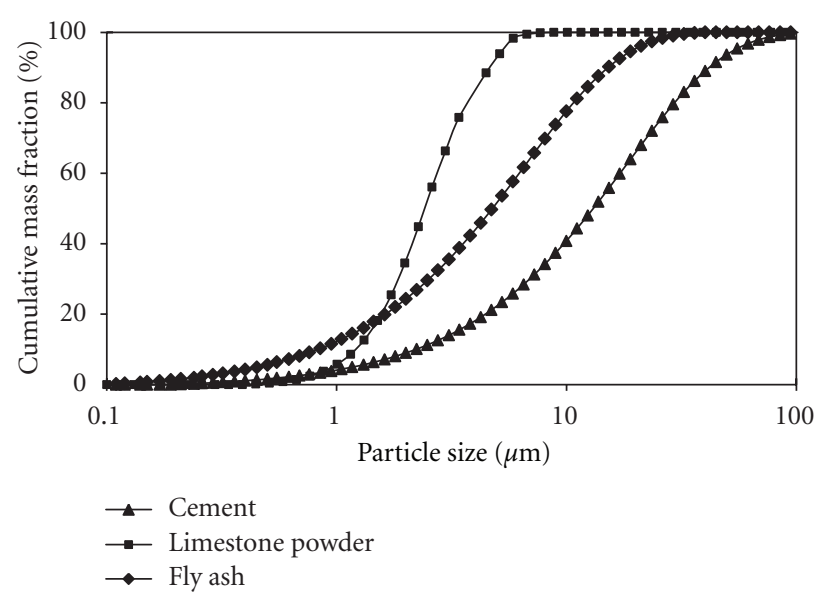

Figure 1: Particle size distributions of cement, limestone powder and fly ash.

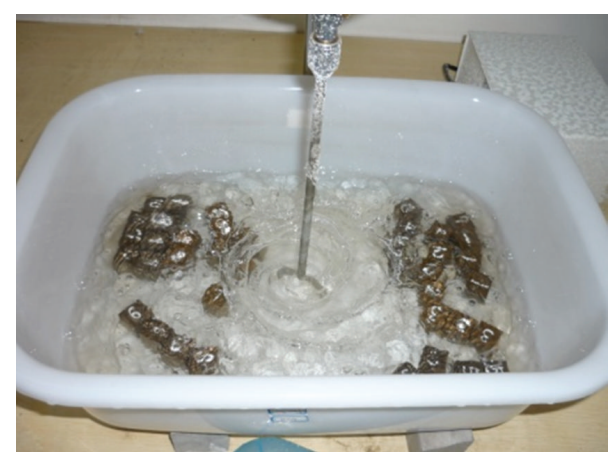

(a) acetic acid attack

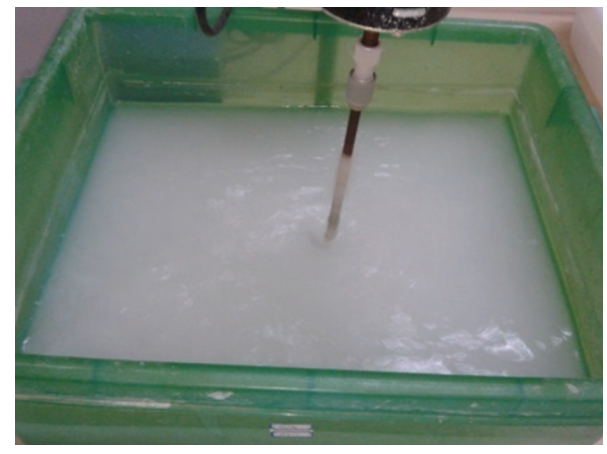

(b) sulfuric acid attack

Figure 2: Devices of simulating flowing (a) acetic acid solution and (b) sulfuric acid solution.

powder. Strength of the pastes incorporating fly ash and silica fume declines more slowly than that of pastes only containing limestone powder.

Figures 3 and 4 show the early strength of pastes decreases in flowing acetic acid solution because calcium hydroxide and calcium carbonate reacted with the acid and the product calcium acetate will leach out. Then unhydrated cement particles continue their hydration which leads pastes' strength to recover slightly. At last, with the further acetic acid attack into the interior, calcium hydroxide will be consumed and 
TABLE 1: Mix proportion of the cement pastes.

\begin{tabular}{lcccccc}
\hline Sample & Water-binding materials & Water & Cement & Limestone powder & Flying ash & Silica fume \\
\hline L-1 & 0.3 & 0.3 & 1 & 0 & 0 & 0 \\
L-2 & 0.3 & 0.3 & 0.7 & 0.3 & 0 & 0 \\
L-3 & 0.3 & 0.3 & 0.5 & 0.5 & 0 & 0.25 \\
L-4 & 0.3 & 0.3 & 0.5 & 0.25 & 0 & 0 \\
L-5 & 0.3 & 0.3 & 0.5 & 0.4 & 0 & 0 \\
\hline H-1 & 0.5 & 0.5 & 1 & 0 & 0 \\
H-2 & 0.5 & 0.5 & 0.7 & 0.3 & 0 \\
H-3 & 0.5 & 0.5 & 0.5 & 0.25 & 0 \\
H-4 & 0.5 & 0.5 & 0.5 & 0.4 & 0.25 \\
H-5 & 0.5 & 0.5 & 0.5 & & 0 \\
\hline
\end{tabular}

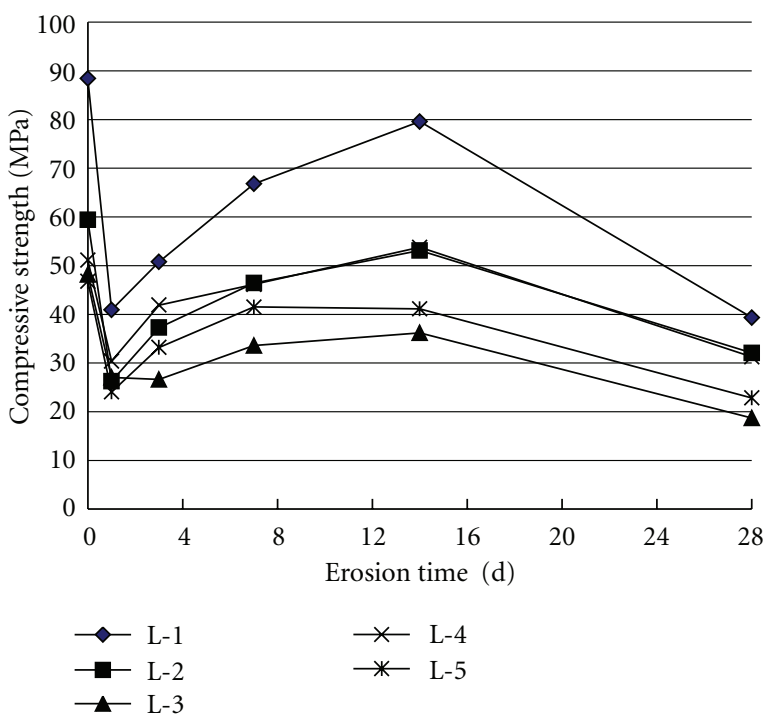

Figure 3: Compressive strength of pastes with $W / B=0.3$ soaked in flowing acetic acid solution over different time.

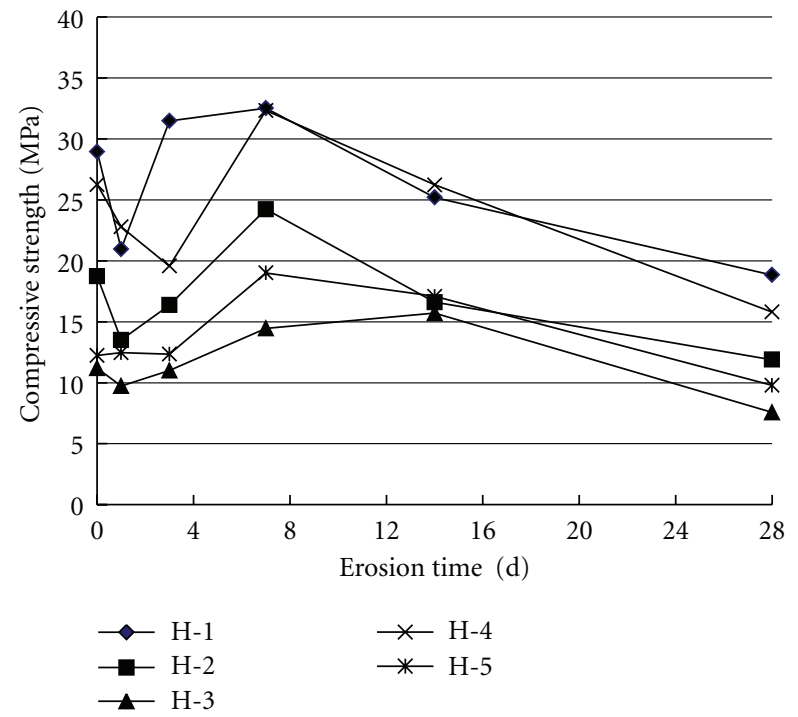

FIGURE 4: Compressive strength of pastes with $W / B=0.5$ soaked in flowing acetic acid solution over different time. calcium carbonate will be dissolved. Thereafter other hydration products decomposed and as a result the strength descended again.

Figures 5 and 6 show the early strength of pastes decreases in the flowing sulfuric acid solution, possibly because calcium hydroxide and calcium carbonate in the pastes reacted with the acid and the products leach out. Then unhydrated cement particles' proceeding hydration and the swelling effect of the generated gypsum lead the pastes strength to recover slightly. At last, with the further sulfuric acid attack into the interior, simultaneously the generated gypsum destroys the pastes' structure and consequently the strength descends again. In comparison with the flowing acetic acid solution, strength of the pastes soaked in the flowing sulfuric acid solution declines more slowly possibly due to the depression effect of the flowing liquid onto the gypsum's crystallization which is commonly the main reason to cause expansion of the paste under sulfuric acid attack. As is indicated in Figure 2, the feculent sulfuric acid solution, unlike the clear appearance presented in the acetic acid solution, suggests gypsum was dissolved out. The pictures provide a convincing demonstration of the explanation.

As for the influence of water-binder ratio, pastes with high $W / B$ value are more easily to be damaged because of their loose microstructure and high porosity. As for the effect of limestone powder, the higher the content, the more paste strength decreases because calcium carbonate, dominant composition of the limestone powder, could react with the acid and the reaction products will leach out. When mixed with an additional cementing material, fly ash, or silica fume, the descending tendency of strength is not that intense because the content of limestone powder decreases. What is more, both fly ash and silica fume could react with calcium hydroxide and the hydration products are beneficial to enhance the strength. Subsequently, the content of calcium hydroxide decreases and so is its degree of reaction with the sulfuric acid.

3.2. Microstructure. Figure 7 shows the results of XRD analysis of hydrates of cement pastes with $W / B$ value of 0.5 soaked in the flowing acetic acid solution at $28 \mathrm{~d}$. There are calcium carbonate peak caused by the mixing of limestone powder and calcium hydroxide peak caused by the hydration. 


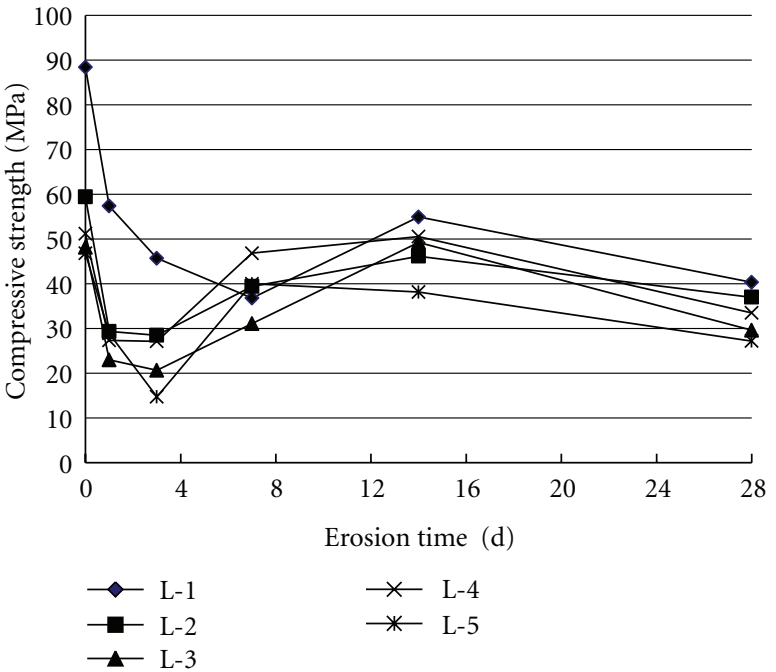

FIGURE 5: Compressive strength of pastes with $W / B=0.5$ soaked in flowing sulfuric acid solution over different time.

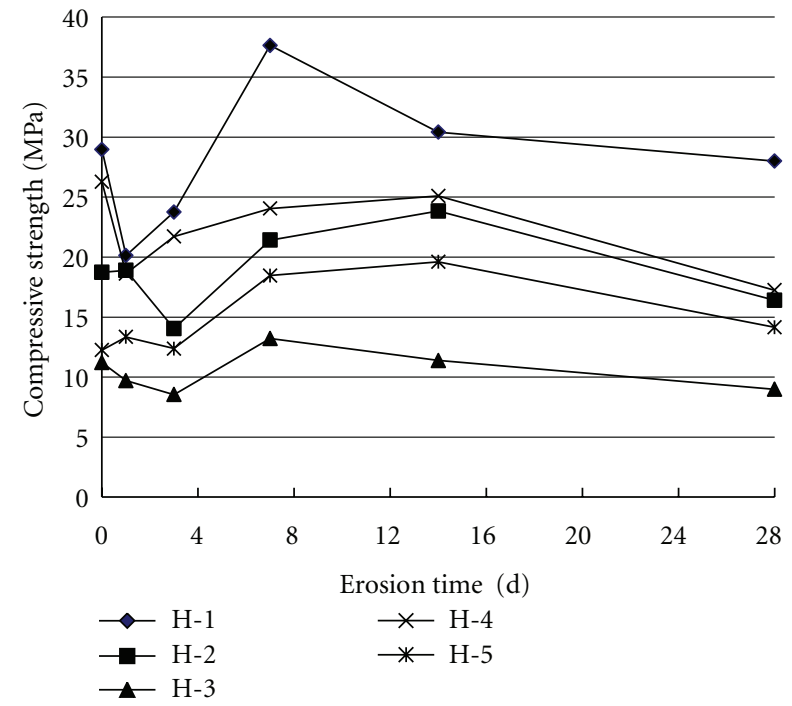

FIGURE 6: Compressive strength of pastes with $W / B=0.5$ soaked in flowing sulfuric acid solution over different time.

The higher the content of limestone powder, the higher the calcium carbonate peak. Calcium carbonate peak is much higher than calcium hydroxide peak. Calcium hydroxide peak is very low because they are consumed in their reactions with the acetic acid.

Figure 8 shows the results of XRD analysis of hydrates of cement pastes with $W / B$ value of 0.5 soaked in the flowing sulfuric acid solution at $28 \mathrm{~d}$. There are calcium carbonate peak, calcium hydroxide peak, gypsum peak and ettringite peak. Calcium carbonate peak is the highest, and the higher the content of limestone powder, the higher the calcium carbonate peak. Calcium hydroxide peak is very low because they are consumed in their reactions with the sulfuric acid which leads to the generation of gypsum. The gypsum could then react with $\mathrm{C}-\mathrm{A}-\mathrm{H}$ and ettringite is generated. The

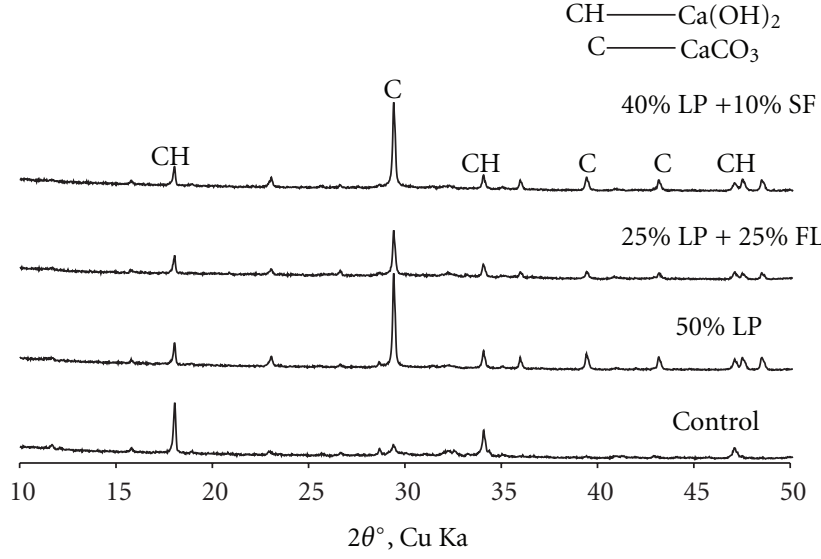

FIGURE 7: XRD patterns of hydrates of cement pastes with $W / B=$ 0.5 soaked in flowing acetic acid solution at $28 \mathrm{~d}$.

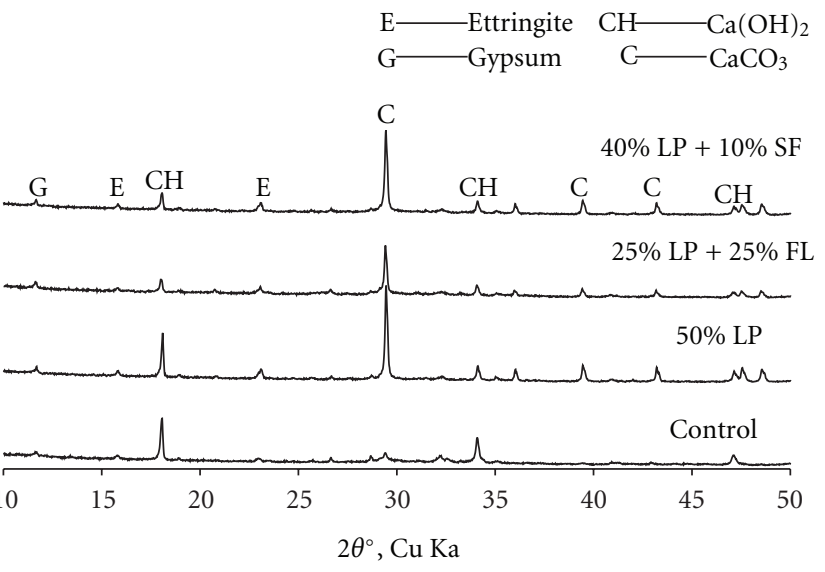

FIGURE 8: XRD patterns of hydrates of cement pastes with $W / B=$ 0.5 soaked in flowing sulfuric acid solution at $28 \mathrm{~d}$.

expansion of pastes caused by gypsum and ettringite should account for the destruction of microstructure and the loss of strength. The figure also indicates that the content of gypsum is relatively low because of the depression effect of the flowing solution onto the gypsum's crystallization. This is consistent with the explanation in the results of strength tests.

Fragments of specimens broken off and washed with acetone were examined by SEM. Figure 9 shows the SEM pictures of sample H-3 soaked in the flowing acetic acid solution at $28 \mathrm{~d}$. C-S-H gel, ettringite and calcium carbonate crystals can be found. But calcium hydroxide crystals are not found because they were consumed in their reactions with the acid. This is consistent with the results of XRD analysis.

Figure 10 shows the SEM pictures of sample $\mathrm{H}-3$ soaked in the flowing sulfuric acid solution at $28 \mathrm{~d}$. C-S-H gel, calcium hydroxide and ettringite crystal can be found in it. But the gypsum is not that much because of the distorting effects of the flowing solution onto the gypsum's crystallization which is consistent with the results of XRD analysis. 


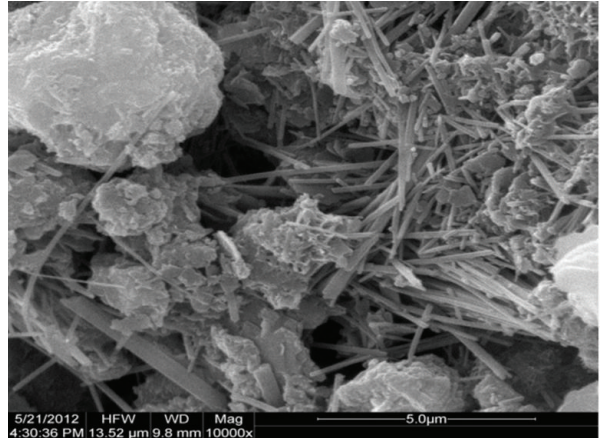

(a)

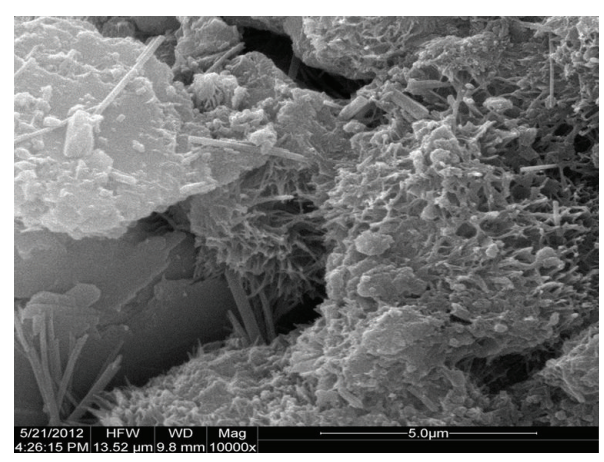

(b)

FIGURE 9: SEM pictures of sample H-3 soaked in flowing acetic acid solution at $28 \mathrm{~d}$.

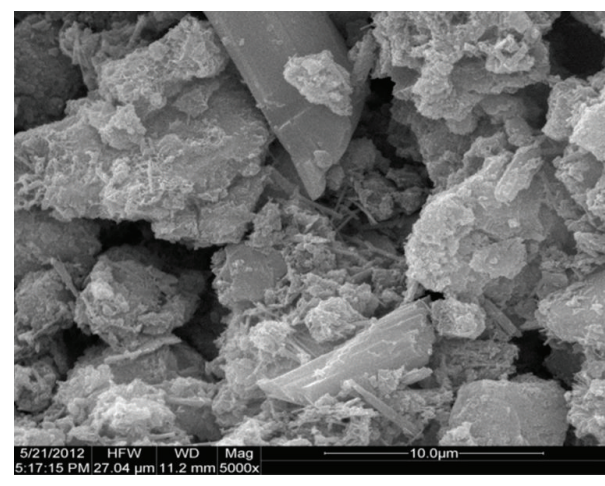

(a)

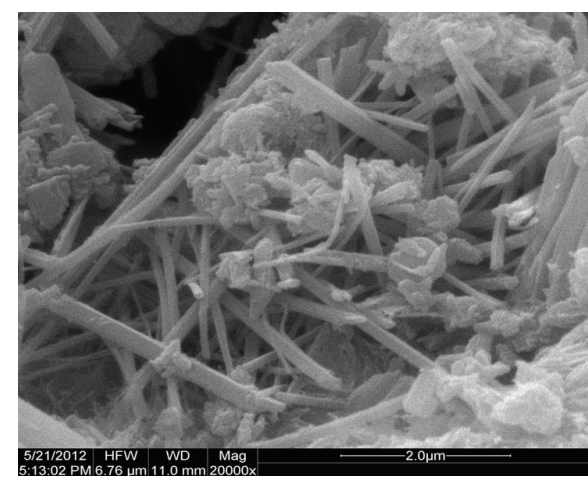

(b)

Figure 10: SEM pictures of sample H-3 soaked in flowing sulfuric acid solution at $28 \mathrm{~d}$.

\section{Conclusions}

(1) The compressive strength of the cement pastes would firstly decrease and then increase slightly and finally decreases again under flowing acid attack. The strength will decrease correspondingly with the increase of the water binder ratio and content of the limestone powder. Strength of pastes mixed with fly ash of silica fume decreases slowly than those of pastes only containing limestone powder.

(2) Cement pastes with high value of $W / B$ are more easily to be damaged because of their loose structure and high porosity. Calcium carbonate in limestone powder could react with the acid and the higher content of it, the faster the strength decreases. When mixed with fly ash or silica fume, they could both react with calcium hydroxide and C-S-H is generated which not only is good to enhance the pastes' strength but also weakens the degree of reactions between the hydration products and the acid.

(3) Microstructural analysis manifests on condition of the flowing acetic acid attack, destruction of the microstructure, and loss of the strength are caused by the reactions between calcium hydroxide and the acid which make the deterioration proceed from the exterior to the interior. While under the flowing sulfuric acid attack, crystallizations of the gypsum and ettringite lead to the expansion of the pastes. The flowing solution environment inhibits the crystallization of gypsum and therefore delays the attack process.

\section{Acknowledgment}

This project was supported by the Fundamental Research Funds for the Central Universities (111039).

\section{References}

[1] S. Liu and P. Yan, "Experimental study on sodium sulfate attack on mortar containing limestone powder and fly ash [C]," in Proceedings of the International Conference on Durability of Concrete Structures, pp. 542-548, Hangzhou, China, November 2008.

[2] S. Liu and P. Yan, "Effect of limestone powder on microstructure of concrete," Journal of Wuhan University of Technology, vol. 25, no. 2, pp. 328-331, 2010.

[3] European Committee for Standardization, "Cement: composition, specifications and conformity criteria, Part 1: Common cements [S]," EN 197-1, EN/TC51/WG 6 rev., 2000. 
[4] M. Schmidt, "Cement with interground materialscapabilities and environmental relief, part 1," ZementKalk-Gips, vol. 45, no. 4, pp. 87-92, 1992.

[5] B. Schiller and H. G. Ellerbrock, "The grinding and properties of cements with several main constituents," Zement-Kalk-Gips, vol. 45, no. 9, pp. 223-231, 1992.

[6] J. Baron and C. Douvre, "Technical and economical aspects of the use of limestone filler additions in cement," World Cement, vol. 18, no. 3, pp. 100-104, 1987.

[7] S. Sprung and E. Siebel, "Assessment of the suitability of limestone for producing Portland limestone cement (PKZ)," Zement-Kalk-Gips, vol. 44, no. 1, pp. 1-11, 1991.

[8] V. Bonavetti, H. Donza, G. Menéndez, O. Cabrera, and E. F. Irassar, "Limestone filler cement in low w/c concrete: a rational use of energy," Cement and Concrete Research, vol. 33, no. 6, pp. 865-871, 2003.

[9] A. Bertron, J. Duchesne, and G. Escadeillas, "Attack of cement pastes exposed to organic acids in manure," Cement and Concrete Composites, vol. 27, no. 9-10, pp. 898-909, 2005.

[10] B. Lothenbach, G. Le Saout, E. Gallucci, and K. Scrivener, "Influence of limestone on the hydration of Portland cements," Cement and Concrete Research, vol. 38, no. 6, pp. 848-860, 2008.

[11] J. Dweck, P. M. Buchler, A. C. V. Coelho, and F. K. Cartledge, "Hydration of a Portland cement blended with calcium carbonate," Thermochimica Acta, vol. 346, no. 1-2, pp. 105$113,2000$.

[12] E. F. Irassar, V. L. Bonavetti, and M. González, "Microstructural study of sulfate attack on ordinary and limestone Portland cements at ambient temperature," Cement and Concrete Research, vol. 33, no. 1, pp. 31-41, 2003. 

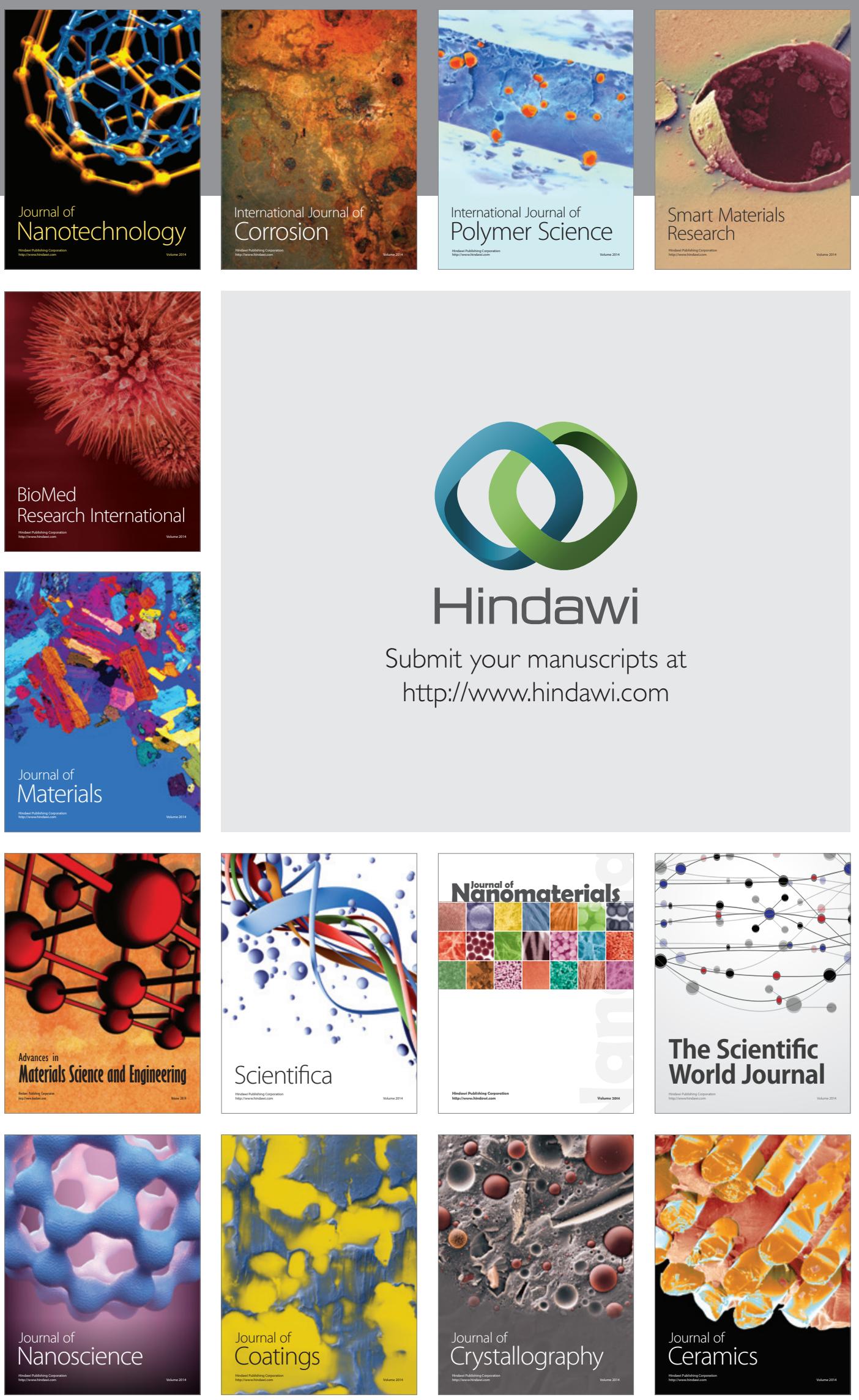

The Scientific World Journal

Submit your manuscripts at

http://www.hindawi.com

\section{World Journal}

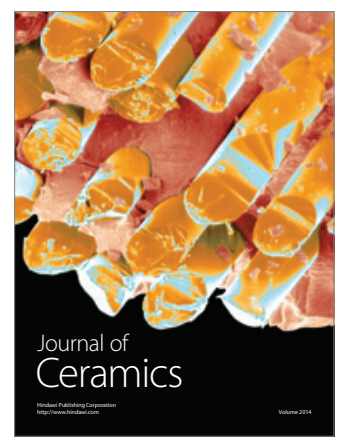

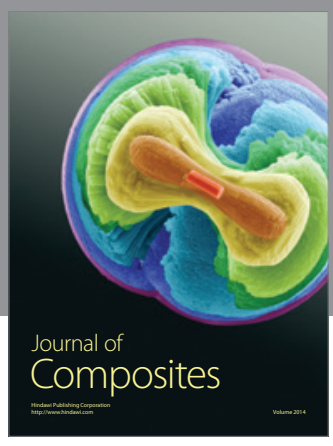
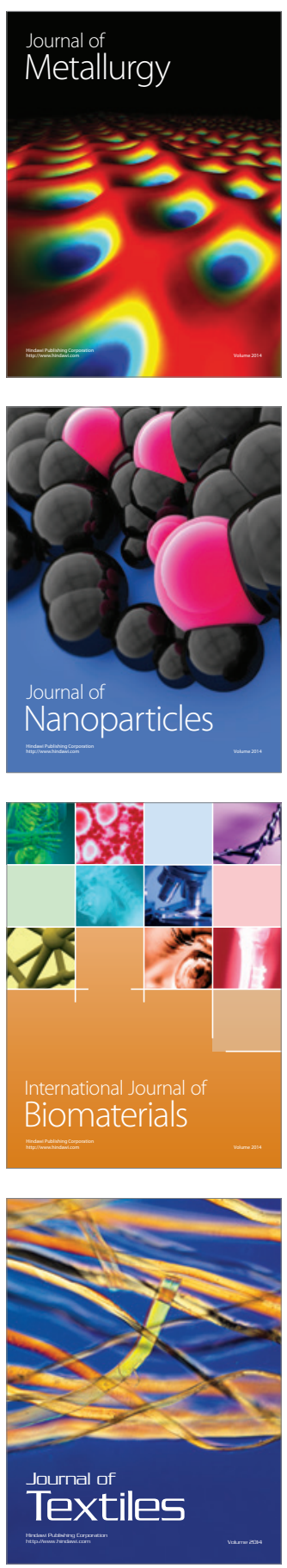